Meteorological Service

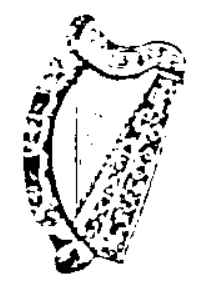

Internal Memorandum no. 111

\title{
ANALYSIS AND PREDICTION OF AIR POLLUTION IN THE DUBLIN AREA
}

\author{
BY \\ R.T. IIC GRATH
}

IRISH ,IETEOROLOGICAL SERVICE

GLASNEVIN HILL

DUBLIN

MARCH 1988 


\section{Summary}

Atmospheric pollutant concentrations in the Dublin area have risen significantly since the late 1970's mainly because of the increased use of coal as a domestic heating fuel. Several years of daily measurements of smoke and sulphur dioxide $\left(\mathrm{SO}_{2}\right)$ gathered from a network of 16 stations covering the city and suburbs are available for study. This paper presents the results of an analysis of the data for the period 1982-1987.

The fluctuations in pollution levels over yearly, weekly and daily time scales were examined and correlated with the weather observed at Dublin Airport. Smoke concentrations were found to be closely related to surface windspeed and air temperature but the connection was more tenuous for $\mathrm{SO}_{2}$.

In Ballyfermot (most smoke-polluted area in Dublin) it appears that background smoke levels have doubled over the period. Similar trends were found in the data from six other sites, the estimated increases ranging from 14 to $70 \%$. In four other cases no significant trend could be found while for the five remaining sites the data suggested decreasing levels (10-40\% decrease). In industrial and non-residential areas daily smoke levels were found to be typically 10-25\% lower over weekends, a possible indication of the contribution made by traffic and industry to the pollution load.

Both smoke and $\mathrm{SO}_{2}$ levels were found to depend on wind direction to some extent but the effects are generally small and probably arise from differences in local exposure or from cross contamination between sites; for mean levels (mean of 16 stations) no directional dependence was apparent.

A forecast model for smoke pollution is described and its performance during the 1987/88 winter season evaluated. Initial results are encouraging and indicate that the Irish Meteorological Service can provide useful forecasts of air quality $24-48$ hours in advance. 


\section{Air Pollution - General Discussion}

\subsection{Emission Sources}

Suspended smoke particles and $\mathrm{SO}_{2}$ can arise from several sources the most important of which in the present context can be summarised as follows:

- Coal burning in open fires (mainly smoke, some $\mathrm{SO}_{2}$ )

- Domestic/industrial burning of fuel oils (mainly $\mathrm{SO}_{2}$ )

- Road traffic (mainly smoke)

While the pollutants are advected locally by wind there is no evidence (see section 4.2.1) to indicate that sources outside the Dublin area have any impact on air quality over the city and suburbs.

From a visual inspection of the data (see Figure 3) it is clear that the two pollutants have quite different characteristics: smoke levels broadly follow the seasonal change in air temperature with peak activity during the winter months December - February; in contrast, differences between the summer and winter values of $\mathrm{SO}_{2}$ are less noticeable. This is consistent with the view that the domestic burning of coal is the chief source of smoke pollution.

While the emission sources can be broadly categorised little is known about their geographical distribution or intensity. More importantly the sources are not constant but respond to the weather in a complex manner. The decision to light a fure for example, or the amount of fuel to burn, depends on factors such as the season of the year and the thermal-comforthealth of the householder. It is impossible to model this response except in a statistical manner.

\subsection{Weather}

Once the pollutants reach the open atmosphere some of the suspended particles will settle on the surface within a shor distance of the source (gravitational settling). The lighter particles and gases will be advected by the wind (if any) and slowly diluted by turbulent processes which may also cause some settling at considerable distances from the source (dry deposition). While turbulence plays a major role in reducing pollution, precipitation is also effective in bringing particles and gases to the surface (precipitation scavenging).

\subsection{Atmospheric Stability}

The earth's surface distorts the atmospheric flow by creating frictional drag through surface roughness and temperature gradients through the absorption of solar radiation. The imbalance is communicated through a turbulent boundary layer within which there is usually vigorous thermal mixing (convection) by day. The depth of the layer varies with the weather but on a fresh sunny afternoon typically reaches $1-2 \mathrm{~km}$. Within the layer, which acts as an effective medium for the dispersion of pollutants, air temperatures will normally decrease with height at a (lapse) rate of around $10^{\circ} \mathrm{C} / \mathrm{km}$ by day. In the absence of solar heating, convection decreases at night and the turbulent (or mixing) layer shrinks in response, possibly to a depth of $100 \mathrm{~m}$ when there is little cloud and the winds are light. With clear skies the ground will cool quickly by radiating heat so that in a layer near the surface (typically $<100 \mathrm{~m}$ in depth) air temperatures will normally increase with height. This inversion of temperature dampens vertical motions and reduces turbulence; pollution released into it (e.g. from a chimney) will show little tendency to mix with the surrounding 
atmosphere or to penetrate to ground level. Such inversions are most developed around dawn but, with solar heating, are usually broken up by late morning on a sunny day. This is a common event in rural areas, particularly in winter, but in an urban setting other factors need to be taken into account.

It is well known that air temperatures in cities are on average slightly higher than those in surrounding rural areas. Possible causes include the high thermal admittance of building materials, the trapping of air in the urban 'canyons', and the release of anthropogenic heat (for a description of the urban heat island, see Oke 1980). In Dublin, temperature contrasts exceeding $6^{\circ} \mathrm{C}$ have been recorded (Sweeny 1987). At night the radiation of the surplus heat generates a turbulent urban boundary layer (UBL) which is carried along by the prevailing winds (see Figure 1). If the atmosphere is stable in the surrounding rural areas (e.g. because of a temperature inversion) then pollution emitted over the city will be locked into the UBL, the thickness of which determines the local concentration.

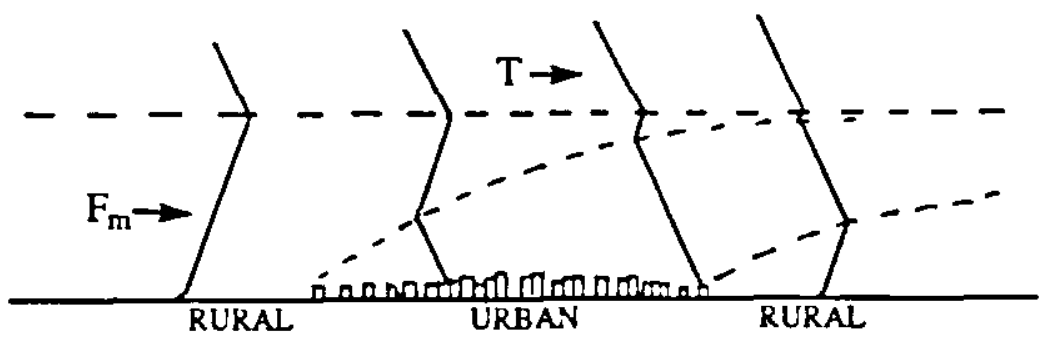

Figure 1: Schematic representation of urban boundary lajer (after Oke 1978).

By making some simplifying assumptions the mean thickness $H$ of the UBL can be shown (Satyanarayana 1986) to be related to windspeed $F_{m}$ as follow's:

where

$$
H=K\left(\left(\Gamma_{0}-\Gamma F_{m}\right)^{-1 / 2}\right.
$$

$$
\begin{aligned}
& \Gamma=\text { Rural lapse rate } \\
& \Gamma_{0}=\text { Dry adiabatic lapse rate }\left(9.8 \times 10^{-3} \mathrm{o} C / \mathrm{m}\right) \\
& F_{\mathrm{m}}=\text { Mean windspeed through the layer. }
\end{aligned}
$$

The value of the constant $K$ depends on the size of the city and the amount of waste heat generated. Because of the multiplicity of emission sources normally encountered within a city the pollutants can, as a first approximation, be regarded as homogeneously distributed over a small area. Under these conditions the local concentration $\mathrm{C}$ can be shown (Oke 1978) to be inversely proportional to $H$ and $F_{m}$ :

$$
\mathrm{C}=\mathrm{S} /\left(\mathrm{HF}_{\mathrm{m}}\right)
$$

or

$$
\mathrm{C}=(\mathrm{S} / \mathrm{K}) \cdot\left(\left(\Gamma_{0^{-}} \Gamma\right) / \mathrm{F}_{\mathrm{m}}\right)^{1 / 2}
$$

where $S$ is a constant describing the emission sources.

High levels of pollution are therefore associated with low windspeeds in a stable atmosphere (temperature inversion). 
Inversions can also develop above the surface through other means. In anticyclonic weather large scale subsidence occurs, the descending air warming adiabatically. If the surface is also cooling (i.e. clear skies at night) stability in the lower layers will be further strengthened with detrimental effects on pollution levels. Unfortunately anticyclones are also associated with light winds which explains why high levels of pollution usually occur in cold settled weather.

A more complete description of atmospheric dispersion requires a detailed knowledge of the wind, temperature and humidity fields in the horizontal and vertical, information which is not generally available for Dublin.

\section{Data}

\subsection{Pollution Data}

Monitoring stations under the control of Dublin Corporation and Dublin County Council have been measuring daily mean concentrations of smoke and $\mathrm{SO}_{2}$ for several years. The sites are listed in Figure 2 where the mean concentrations for the 1986/1987 winter season are also displayed. The maps should be viewed as merely representative since there is considerable spatial and temporal variation in the pollution levels as is evident from an examination of the individual records (Figure $3)$.

For practical reasons the study was restricted to data recorded within the period Ist January 1982 to 31st March 1987. For sites nos. 12-17 data were only available from 1st April 1982 onwards while for site no. 11 (old County Road) records commence from the 4th April 1985.

\subsection{Meteorological Data}

Unfortunately, detailed weather observations are not available at any of the listed sites. The nearest meteorological station is situated in Dublin Airport from which hourly observations are made of temperature (at $1.2 \mathrm{~m})$, wind (at $10 \mathrm{~m})$, pressure, rainfall and cloudiness. No vertical soundings of the atmosphere are taken and stability must therefore be estimated indirectly from existing surface observations.

Data from weather stations which measure the vertical profiles of wind, temperature and humidity can be interpolated to Dublin but as the nearest station is in Long Kesh, over $100 \mathrm{~km}$ distant, the resolution of the data is too low to be of use.

In the present study it was assumed that the pollution levels are related in a statistical sense to the reference weather recorded at Dublin Airport. Cloud and precipitation amounts within the network area may differ appreciably from the reference values and even the more conservative temperature and wind elements will be influenced by factors such as site exposure and the scale of the UBL (see Draxler 1986 for an interesting case study).

\section{Analysis of Data}

\subsection{Method}

Data from each of the stations were subjected to a multiple regression analysis using a stepwise regression procedure with a $99 \%$ significance level for the F-test (Draper and Smith 1981).

Potential predictors for the model were derived from the meteorological observations along with 
non-meteorological variables such as the day number $(1=1 \mathrm{st}$ January, $365=31$ st December $)$. Since the smoke/ $\mathrm{SO}_{2}$ measurements are essentially mean concentrations over a 24 hour period (midnight to midnight) it makes sense to use a similarly defined mean for the meteorological predictors. Other averaging periods such as noon to midnight and sunrise to sunset were tried, as were maximum and minimum values, but no significant advantage could be demonstrated to justify their use. Therefore, unless otherwise stated, mean values refer to a 24 hour period, midnight to midnight.

Up to 25 potential predictors were tried in the regression and the most significant of these (a maximum of 10 ) selected. The selection mechanism is based on the assumption that the errors are independent, have zero mean, a constant variance, and are normally distributed. These conditions were tentatively checked by examining plots of the residuals and if necessary recasting the model to obtain a better fit. In most cases the dependent variable (i.e. smoke/ $\mathrm{SO}_{2}$ levels) were transformed initially by taking the logarithm of the readings.

\subsection{Regression Model}

It is reasonable to assume that the emission levels are closely related to the weather and in particular to the air temperature (T): as the extemal temperature falls nore fires are lit and a greater amount of fuel is burnt to make up the additional heat loss. This is obviously a generalization since the human response does not always keep pace with swings in temperature, particularly when the weather is changing rapidly. A preliminary examination of the data suggested a non linear dependence on $T$ and better results were usually achieved by including an empirical variable of the form

$$
(T+9)^{-1 / 2}
$$

in the regression equation ( $\mathrm{T}$ in Celsius).

Windspeed dependence (see section 1.3) was modelled by using the predictor

$$
(\mathrm{F}+\mathrm{B})^{-1 / 2}
$$

where $F$ is the $10 \mathrm{~m}$ windspeed. The constant $\mathrm{B}$ allows for the fact that the mean windspeed in the UBL differs from $F$. Best results were obtained using $B=4\left(F\right.$ in $\left.\mathrm{ms}^{-1}\right)$.

In the absence of temperature readings in the vertical, stability was inferred from the Pasquill-Turner stability categories which are derived from surface observations (Pasquill 1961, Tumer 1964). To facilitate the analysis the digits 1-7 were used to describe the stability instead of the more usual categories A-G (very unstable-very stable).

\section{Results}

\subsection{Yearly Trends}

While the emission sources fluctuate daily in response to the weather, social and economic forces are also at work over longer time scales slowly changing the pollution pattern. Estimates of coal consumption in the Dublin area between 1982 and 1986 (Reilly 1986), for example, suggest that the sources have increased over the period.

To highlight any possible trends both predictand (i.e. smoke/SO 2 ) and predictors were filtered prior to regression by using 7 day moving average values. Results for a typical site (Ballyfermot) are shown in Table 1 for smoke pollution. The model fits the data quite well, explaining more than $90 \%$ of the data variance. There is also considerable evidence of a linear trend in the data (predictor Y'). 
Since $\mathrm{Y}$ is essentially independent of the other predictors we can isolate the trend as follows:

$$
\log _{i}\left(S / S_{1982}\right)=0.1486+0.0048 Y
$$

where $Y$ is the year relative to 1982 and $S$ is the smoke concentration. Substituting $Y=5$ (for 1987) gives

$$
S_{1937} / S_{1982}=2.10 \pm .05
$$

A similar analysis was performed for each of the 16 monitoring sites (Old County Rd. was excluded because of insufficient data) and the essential details are summarised in Table 3 . For sites which yielded a positive $Y$ coefficient the estimated increases over the five year period are as follows:

$\begin{array}{lc}\text { Site } & \text { cIncrease (smoke) } \\ \text { Ballyfermot } & 110 \pm 5 \\ \text { Bluebell } & 70 \pm 8 \\ \text { Clondalkin } & 67 \pm 6 \\ \text { Cappagh } & 48 \pm 8 \\ \text { South Quay } & 40 \pm 6 \\ \text { Mountjoy Su. } & 19 \pm 4 \\ \text { Rathmines } & 14 \pm 4\end{array}$

For four of the sites (viz. Clontarf, Herben St., Cabra, and Dundrum) there is no evidence of any trend, while in five cases the trend was found to be negative (i.e. decrease):

$\begin{array}{lc}\text { Site } & \text { \%Decrease (smoke) } \\ \text { Tallaght } & 40 \pm 2 \\ \text { Dun Laoghaire } & 38 \pm 2 \\ \text { Swords } & 16 \pm 3 \\ \text { Ballsbridge } & 13 \pm 3 \\ \text { Dame Street } & 10 \pm 2\end{array}$

These results, based on the assumption of a linear trend, should be taken as approximate and balanced against the percentage variance explained by the model.

Similar attempts to analyse the $\mathrm{SO}_{2}$ readings were less successful - the model invariably suffered from a 'lack of fit' and the results are not shown.

\subsection{Daily Values}

\subsubsection{Wind Direction}

To highlight any directional dependence the data from each station were sorted in descending order of magnitude and the wind directions associated with the first fifty observations analysed and compared with those from the 'mean' station. The results are shown in Figure 4.

Clearly there is no preference for any wind direction when the mean smoke (or $\mathrm{SO}_{2}$ ) levels are high; all sectors of the compass are represented. Nevertheless there are significant differences between sites. 
The advection of smoke from the more heavily polluted central areas of the city offers one explanation for the asymmetry in wind distributions but peculiarities of site exposure are also likely to be important. For Ballyfermot (station no. 5) there is clearly a preference for winds between west and north at the expense of those between norheast and southeast; the disparity may have its origin in exposure effects or the thickness of the UBL which, for a site on the edge of the city, is very dependent on wind direction (see Figure 1). The directional characteristics of $\mathrm{SO}_{2}$ pollution are in general quite different from those of smoke and reflect the underlying differences between the emission sources.

It should be remembered that the results refer to Dublin Airport winds; local values, particularly in near calm conditions, may differ appreciably.

One particular wind direction deserves special mention. Cold spells which arise from quasistationary high pressure systems in winter are frequently terminated by freshening southerly or southwesterly winds bringing warm air from the Atlantic. During the cold spell a pool of cold air collects over the city and if sufficiently stable becomes decoupled from the higher levels of the atmosphere. The arrival of warm air, impeded by the sheltering effects of the Wicklow mountains to the south, takes place above the surface. This increases the stability (usually temporarily) and under these conditions surface winds can be very sluggish in responding to the new regime even though a sizeable large scale pressure gradient develops over the area.

A good example of this occurred on the 31 st January 1987. A cold light southeasterly airflow on the 30 th led to sharp cooling overnight under virtually calm conditions with clear skies. Winds freshened slowly from a southerly direction across the country throughout the 31 st but with little effect on Dublin; windspeeds remained light or calm during the day in spite of $8-10 \mathrm{~ms}^{-1}$ being recorded by the Kish lighthouse a short distance off the coast. Mean windspeed and temperature were $1.5 \mathrm{~ms}^{-1}$ and $\mathrm{l}^{\circ} \mathrm{C}$ respectively with a recorded smoke concentration of $1429 \mu \mathrm{g} / \mathrm{m}^{3}$ in Ballyfermot.

\subsubsection{Day of the W'eek}

An attempt was made to indirectly estimate the smoke emissions arising from vehicular traffic and industry by searching the data for differences between weekend and weekday smoke levels. This was carried out by incorporating a dummy variable $W$ in the regression analy'sis where

$$
\begin{aligned}
\mathrm{W} & =1 \text { (weekend) } \\
& =0 \text { (weckday) }
\end{aligned}
$$

The results are summarised in Table 3.

For some sites (Ballyfermot included) no difference could be found but in all other cases the coefficient of $W$ was negative (i.e. less pollution over the weekend). The differences are most noticeable in the industrial areas of the city.

The complete analy'sis of the daily mean smoke pollution levels in Ballyfemot is shown in Table 4 from which it is evident that temperature and windspeed are the most important meteorological predictors. A rather surprising result is the lack a precipitation term in the regression equation; neither daily amounts or duration were found to be significant. Other studies (Patrinos and Binkowski 1986) would lead one to expect a substantial reduction of levels during rain episodes but since the higher levels of pollution occur during settled weather the precipitation effects are minor in comparison to those of windspeed and temperature. 
The mean Pasquill-Tumer index, which is dependent on cloud height and amount, has only a small influence on smoke levels and demonstrates the need for a more comprehensive description of atmospheric stability.

\section{Forecasting Smoke Pollution}

There are two main obstacles to developing a successful method for forecasting smoke pollution. First, we have no way of knowing whether the trends discussed in section 4 will continue; it is quite possible for example that the background levels in Ballyfermot have now saturated. Second, some of the weather elements are notoriously difficult to predict (e.g. cloud cover, dewpoint temperature) and will therefore degrade the quality of forecasts if they are included in a prediction equation.

To overcome these difficulties a regression model was developed from the Ballyfermot data using the two most recent years (1985-1987) of winter data (October-March). Potential meteorological predictors were restricted to mean temperature $(\mathrm{T})$ and windspeed $(\mathrm{F})$ with no allowance for time trends. In view of the critical dependence of smoke levels on windspeed the model was split into two parts and ultimately took the following form:

$$
\begin{gathered}
F \leqslant 4 \mathrm{~ms}^{-1} \\
\log _{\mathrm{e}}(\text { Smoke })=2.8958+3.43963(1+\mathrm{F} / 4)^{-1 / 2}(1+\mathrm{T} / 9)^{-1 / 2}+0.6277 \cos \mathrm{D} \\
\mathrm{F}>4 \mathrm{~ms}^{-1} \\
\log _{\mathrm{c}}(\text { Smoke })=8.2983+5.09962(1+\mathrm{F} / 4)^{-1 / 2}(1+\mathrm{T} / 9)^{-1 / 2}+0.4849 \cos \mathrm{D} \\
-6.8208(1+\mathrm{T} / 9)^{-1 / 2}-0.1468 \mathrm{~T}
\end{gathered}
$$

where $\mathrm{D}=2 \pi($ Day -7$) / 365$, Day = Day of the year.

Forecast values of $F$ and $T$ can be derived from the near surface weather products output from the global computer forecast model run at the European Centre for Medium Range Weather Forecasts (ECMIVF) in Reading, England. Forecasts are disseminated each day for projected weather up to 10 days ahead at intervals of 6 or 12 hours. Mean values of $F$ and $T$ are calculated from the products and statistically optimised for Dublin prior to use. Starting in November 1987 the model has been used operationally by the Irish Meteorological Service to provide guidance on air quality over Dublin. Figure 5 shows a comparison between observed and forecast ( 24 hour) values for a selected period.

The forecasts are obviously not perfect but they do give a general indication of likely smoke levels and successfully predicted the high pollution recorded on the 9th and 10th of December 1987. The sample correlation coefficient and root mean square error were 0.79 and $89 \mu \mathrm{g} / \mathrm{m}^{3}$, respectively, which compare favourably with the values of 0.55 and $141 \mu \mathrm{g} / \mathrm{m}^{3}$ for unskilled 'persistance' forecasts. Accurate wind forecasts are essential and therefore appear to limit the usefulness of the model to a lead time of around 48 hours. Best results are likely to be obtained in settled (e.g. anticyclonic) weather. When the windspeeds are changing, the mean value for $F$ will probably underestimate concentrations. This is particularly relevant when a change of airmass occurs. A small ridge of high pressure following the passage of a cold front, for example, can lead to almost calm conditions for a few hours and a sharp decline in air quality until the front has moved well away from the city.

It must be emphasised that smoke concentrations are highly variable even over a small area; on any 
particular day local levels can vary by a factor of 10-20, even for sites whose yearly mean values are similar. Instead of forecasting for a single point an alternative approach is to develop a model based on the mean of data from a number of sites. This was tried but appeared to be less successful, probably because each site has its own pollution signature and the effect of averaging smooths the data too much.

\section{Future Developments}

The global analysis/forecast model at ECMWF calculates weather elements on a quasi-regular horizontal grid (grid size $=1.125$ degrees of latitude) and at 19 levels in the vertical. The lowest three levels correspond roughly to 30,150 and $400 \mathrm{~m}$ above the model surface (which is an approximation to the earth's surface). Forecast and analysed weather products at these levels are now available and even though the resolution of the global model is too crude to describe the microclimate of Dublin the additional data may improve our capability of forecasting atmospheric stability.

To pursue the matter further requires

(1) A more detailed knowledge of the emission sources and their variation in response to weather and season. The results of a survey carried out by Dublin Corporation in early 1988 on the heating habits of people in the Ballyfermot area should partially fill this gap.

(2) More detailed pollution measurements. Present values are 24 hour averages whereas higher instantaneous values undoubtedly occur during episodes of high pollution, particularly in the evening when the output from domestic fires reaches a peak.

(3) More detailed weather observations i.e. temperature and wind profiles within the lowest $100 \mathrm{~m}$ of the atmosphere over Dublin.

\section{Acknowledgements}

Data for the study were provided by Dublin Corporation and Dublin County Council. During the $1987 / 88$ winter season the Corporation also provided daily pollution measurements from Ballyfermot and other sites - information which proved to be invaluable in assessing the accuracy of the forecast model.

\section{References}

Draper, N.R. and H. Smith (1981): Applied Regression Analysis. New York: Wiley

Draxler, R.R (1986): Measured influence of the nocturnal heat island on pollutant transport. Proceedings Fifth Joint Conference on Applications of Air Pollution Mcteorology, AMS/APCA, 1821 November, 1986, Chapel Hill, N.C., USA.

Oke, T.R. (1982): The energetic basis of the urban heat island. Quart. J. R. Met. Soc. (1982), 108, pp.1-24.

Oke, T.R. (1978): Boundary Layer Climates. London: Methuen.

Pasquill, F. (1961): The estimation of the dispersion of wind borne material. Met. Mag., 90, 33-49.

Patrinos, A.N. and F.S. Binkow'ski (1986): Episodic coincident air quality and precipitation 
measurements in an urban setting. Proceedings Fifth Joint Conference on Applications of Air Pollution Metcorology, AMS/APCA, 18-21 November, 1986, Chapel Hill, N.C., USA.

Reilly, P. (1986): National coal consumption Figures 1976-1986. Dublin Corporation Environmental Pollution Report 1986:87, pp.103-104.

Satyanarayana, B. (1986): Theoretical estimation of urban moming mixing height. Proceedings Fifth Joint Conference on Applications of Air Pollution Meteorology, AMS/APCA, 18-21 November, 1986, Chapel Hill, N.C., USA.

Sweeney, J. (1987): The Urban Heat Island of Dublin City. Irish Geography,.20, pp. 1-10

Turner, D.B. (1967): A diffusion model for an urban area. JAppl.Met., 3, 83-91. 

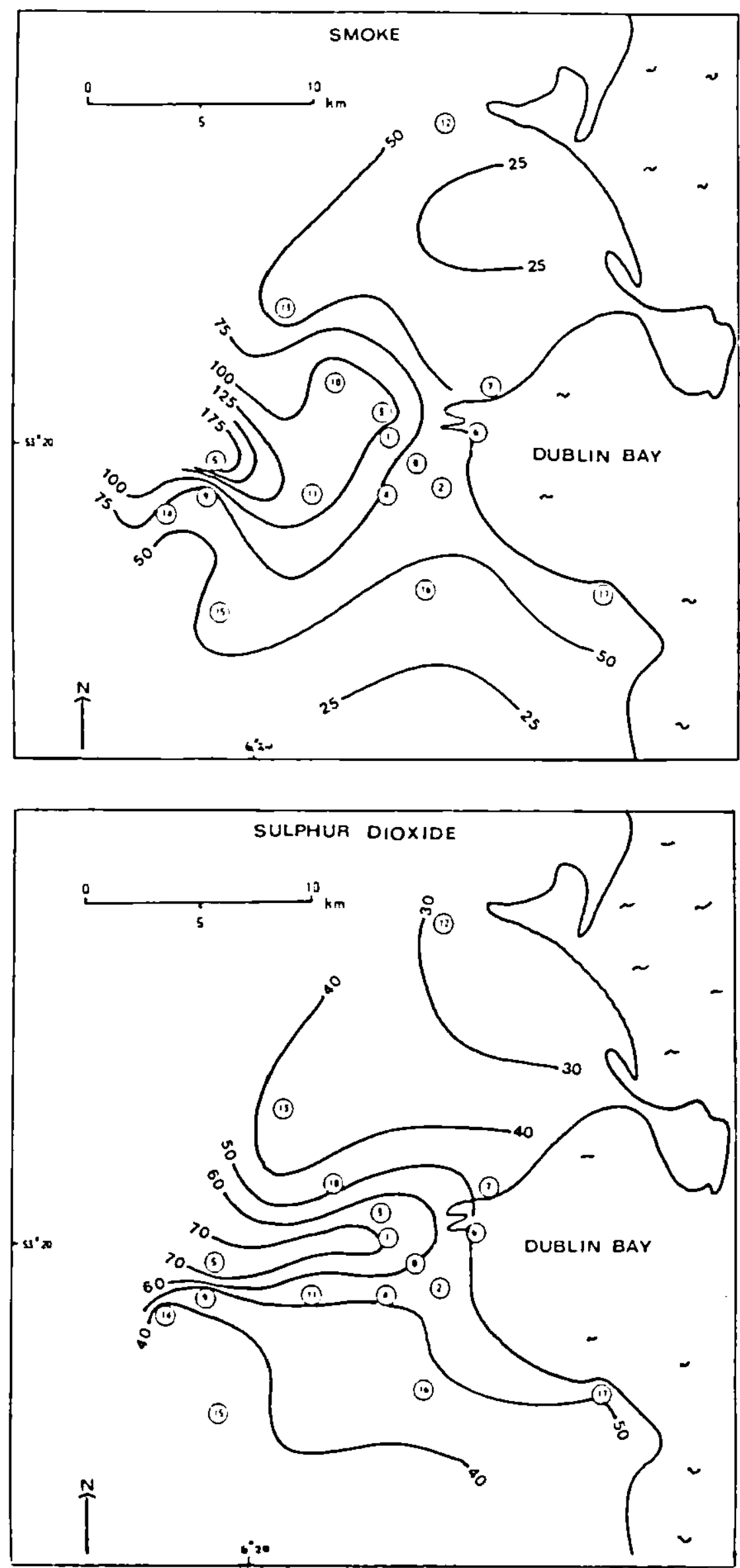

(1) DAME ST.

(2) R.D.S BALISBRIDGE

(3) MOUNTJOY SQUARE

(4) RATHMINES RD.

(5) GARRYOWEN RD. BALLYFERMIOT

(6) HAILING STATION SOUTH QUAY

(7) CLONTARF

(8) HERBERT ST.

(9) BLUEBELL L'DUSTRIAL ESTATE

(10) BROOMIBRIDGE RD. CABRA WEST

(11) OLD COUNTY RD.

(12) SWORDS

(13) CAPPAGH

(14) CLONDALKIV

(15) TALLAGHT

(16) DUNDRUM

(17) DUN LAOGHAIRE

Figure 2 Mean smoke and sulphur dioxide concentrations $\left(\mu \mathrm{g} / \mathrm{m}^{3}\right)$ for $1986 / 87$ winter months. 

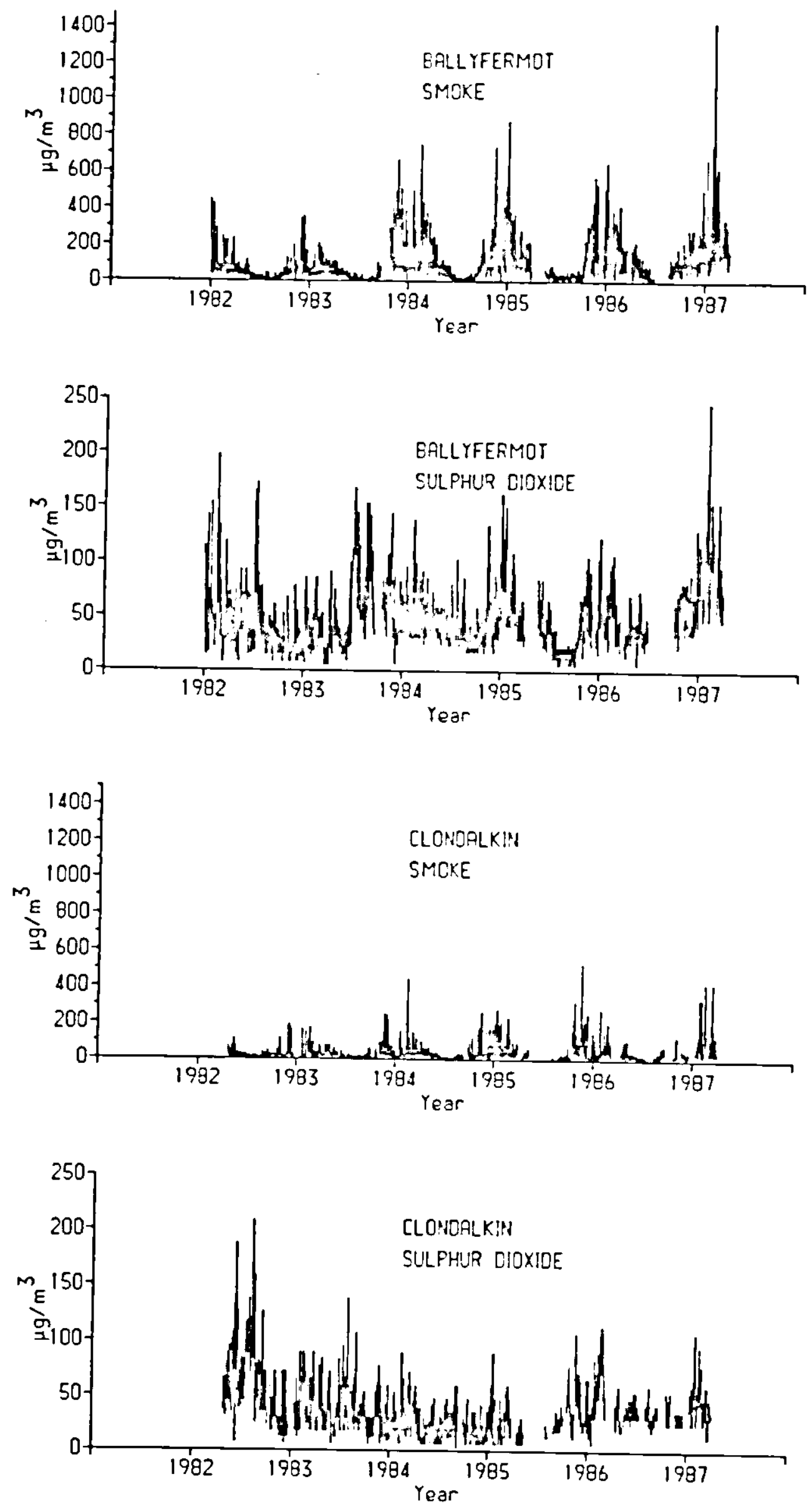

Figure 3 Daily mean concentrations of smoke and sulphur dioxide $\left(\mu \mathrm{g} / \mathrm{m}^{3}\right)$ recorded in Ballyfermot and Clondalkin, Dublin. 


(3)<smiles>CC(C)(C)C(C)(C)C</smiles><smiles>CC(C)(C)C(C)(C)C</smiles>

Figure 4 Relative frequency of wind directions during episodes of high smoke/ $/ \mathrm{SO}_{2}$ pollution. Climate refers to the period 1982-1987 (all weather conditions). 


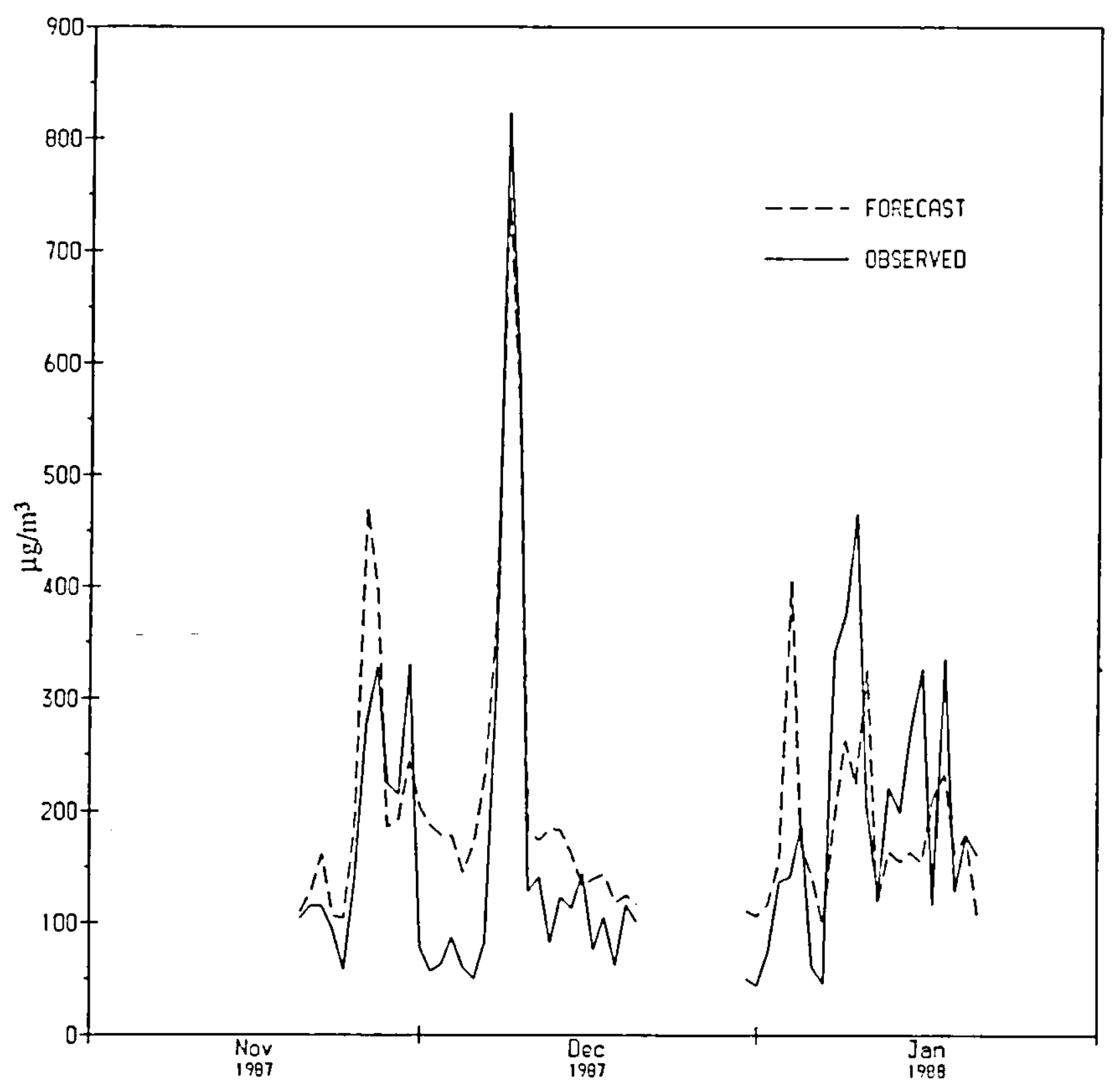

Figure 5 Comparison between observed and forecast ( 24 hour) daily mean smoke concentrations for Ballyfermot. 
REGRESSION ANALYSIS OF BALLYFERMIOT SMOKE POLLUTION DATA

RESPONSE VARIABLE: LOG (MEAN SMOKE CONCENTRATION)

\begin{tabular}{|l|c|c|c|}
\hline PREDICTOR & COEFFICIENT & $\begin{array}{c}\text { STANDARD } \\
\text { ERROR }\end{array}$ & $100 R^{2}$ \\
\hline $\cos (\mathrm{D})$ & 0.6497 & 0.0250 & 69.9 \\
\hline $\mathrm{Y}$ & 0.1486 & 0.0048 & 76.7 \\
\hline$(1+\mathrm{T} / 9)^{-1 / 2}(1+\mathrm{F} / 4)^{-1 / 2}$ & 4.0817 & 0.2067 & 82.0 \\
\hline $\cos (2 \mathrm{D})$ & -0.1515 & 0.0131 & 86.0 \\
\hline $\sin (2 \mathrm{D})$ & -0.1117 & 0.0112 & 87.9 \\
\hline$T_{\mathrm{d}}$ & -0.0557 & 0.0097 & 88.4 \\
\hline$(1+\mathrm{T} / 9)^{-1 / 2}$ & -8.0577 & 0.5546 & 89.4 \\
\hline$T$ & -0.2112 & 0.0127 & 89.8 \\
\hline$P$ & 0.4050 & 0.0719 & 90.1 \\
\hline $\sin (\mathrm{D})$ & -0.0785 & 0.0151 & 90.3 \\
\hline
\end{tabular}

Constant Term in Prediction Equation: 8.0320

No. of observations: $\quad 1790$

Standard deviation of residuals: $\quad 0.3008$

Percentage variation explained $\left(\mathrm{R}^{2}\right): 90.29$

Notes:

$\mathrm{Y}=($ Year-1982)

$\mathrm{D}=2 \pi(\mathrm{DAY}-7) / 365$ where DAY $=$ Day of year $(1$ on January $1 \mathrm{st})$

$\mathrm{T}=$ Mean temperature $\left({ }^{\circ} \mathrm{C}\right)$

$T_{d}=M$ lean dewpoint temperature $\left({ }^{\circ} \mathrm{C}\right)$

$F=M e a n$ surface windspeed $\left(\mathrm{ms}^{-1}\right)$

$P=$ Mean Pasquill-Turner stability index

Table 1 Multiple regression analysis of smoke pollution data for Ballyfermot. Smoke and meteorological values $\left(\mathrm{T}, \mathrm{F}, \mathrm{P}, \mathrm{T}_{\mathrm{d}}\right)$ are 7 day moving averages. 
REGRESSION MODEL

"Y" VARIABLE

\begin{tabular}{|c|c|c|c|c|}
\hline STATION & $N$ & $\begin{array}{c}\text { PERCENTAGE } \\
\text { VARIATION EXPLAINED }\left(\mathrm{R}^{2}\right)\end{array}$ & COEFFICIENT & $\begin{array}{l}\text { STANDARD } \\
\text { ERROR }\end{array}$ \\
\hline (1) & 1915 & 79.15 & -0.0223 & 0.0044 \\
\hline (2) & 1914 & 68.43 & -0.0288 & 0.0063 \\
\hline (3) & 1912 & 84.34 & 0.0339 & 0.0059 \\
\hline (4) & 1891 & 81.06 & 0.0282 & 0.0058 \\
\hline (5) & 1790 & 90.18 & 0.1475 & 0.0048 \\
\hline (6) & 1771 & 74.10 & 0.0673 & 0.0074 \\
\hline (7) & 1915 & 85.67 & - & - \\
\hline (8) & 1872 & 83.06 & - & - \\
\hline (9) & 1904 & 71.81 & 0.1058 & 0.0083 \\
\hline (10) & 1825 & 83.94 & - & - \\
\hline (I1) & & INSLFFICIENT DATA -..- & & \\
\hline (12) & 1639 & 80.49 & -0.0346 & 0.0062 \\
\hline (13) & 1514 & 67.45 & 0.0780 & 0.0118 \\
\hline (14) & 1579 & 79.00 & 0.1026 & 0.0071 \\
\hline (15) & 1611 & 82.56 & -0.1013 & 0.0079 \\
\hline (16) & 1657 & 75.81 & - & . \\
\hline (17) & 1753 & 86.53 & -0.0970 & 0.0058 \\
\hline
\end{tabular}

Notes:

$Y=($ Year-1982)

$N=$ No. of observations

Table 2 Trends in mean smoke pollution levels ( 7 day moving averages) based on regression analysis of data for the period 1982-1987. See text for explanation. 
REGRESSION MODEL

"W" VARIABLE

\begin{tabular}{|c|c|c|c|c|}
\hline STATION & $\begin{array}{c}\text { PERCENTAGE } \\
\text { VARIATION EXPLALNED }\left(R^{2}\right)\end{array}$ & COEFFICIENT & $\begin{array}{l}\text { STANDARD } \\
\text { ERROR }\end{array}$ & DIFFERENCE \\
\hline (1) & 54.88 & -0.2435 & 0.0275 & $78 \pm 2$ \\
\hline (2) & 41.94 & -0.2789 & 0.0375 & $76 \pm 3$ \\
\hline (3) & 72.56 & -0.1658 & 0.0296 & $85 \pm 2$ \\
\hline (4) & 67.10 & -0.1436 & 0.0298 & $87 \pm 3$ \\
\hline (5) & 78.27 & - & - & - \\
\hline (6) & 51.64 & -0.1969 & $0.0 \div 32$ & $82 \pm 4$ \\
\hline (7) & 67.13 & - & - & - \\
\hline (8) & 69.83 & - & - & - \\
\hline (10) & 59.34 & $\cdot$ & - & - \\
\hline (11) & --- INSUFFICIENT DATA -- & & & \\
\hline (12) & 56.21 & -0.1785 & $0.03-2$ & $84 \pm 3$ \\
\hline (13) & 53.05 & - & $\cdot$ & - \\
\hline (14) & 62.00 & -0.2148 & 0.0361 & $81 \pm 3$ \\
\hline (15) & 67.53 & - & - & - \\
\hline (16) & 58.66 & - & $\cdot$ & $\cdot$ \\
\hline (17) & 64.59 & - & - & - \\
\hline
\end{tabular}

Notes:

$\mathrm{W}=1$ (weckend) or 0 (weckday)

Table 3 Differences between weekday and weekend daily mean smoke pollution levels. Last column shows the estimated mean weekend levels as a percentage of weekday values. 
RESPONSE VARIABLE: LOG (MEAN SMOKE CONCENTRATION)

\begin{tabular}{|l|c|c|c|}
\hline PREDICTOR & COEFFICIENT & $\begin{array}{c}\text { STANDARD } \\
\text { ERROR }\end{array}$ & $100 \mathrm{R}^{2}$ \\
\hline$T$ & -0.2235 & 0.0154 & 53.5 \\
\hline $\operatorname{Cos}(\mathrm{D})$ & 0.7184 & 0.0303 & 60.1 \\
\hline$(1+\mathrm{T} / 9)^{-1 / 2}(1+\mathrm{F} / 4)^{-1 / 2}$ & 3.7693 & 0.1998 & 65.1 \\
\hline$Y$ & 0.1589 & 0.0032 & 70.1 \\
\hline$(1+\mathrm{T} / 9)^{-1 / 2}$ & -5.7640 & 0.5408 & 74.7 \\
\hline $\operatorname{Cos}(2 \mathrm{D})$ & -0.1944 & 0.0195 & 75.7 \\
\hline $\operatorname{Sin}(2 \mathrm{D})$ & -0.1550 & 0.0179 & 76.5 \\
\hline$D$ & 0.2482 & 0.0333 & 77.3 \\
\hline$T_{d}$ & 0.0682 & 0.0092 & 78.0 \\
\hline$P$ & 0.2394 & 0.0557 & 78.3 \\
\hline
\end{tabular}

Constant Term in Prediction Equation: 6.5321

No. of Obscrvations: $\quad 1742$

Standard Deviation of Residuals: $\quad 0.5118$

Percentage variation explained $\left(\mathrm{R}^{2}\right): \quad 78.27$

Notes:

$Y=($ Year-1982)

$D=2 \pi($ DAY -7$) / 365$ where DAY $=$ Day of year $(1$ on January $1 \mathrm{st})$

$\mathrm{T}=$ Mean temperature $\left({ }^{\circ} \mathrm{C}\right)$

$\mathrm{T}_{\mathrm{d}}=$ Mean dewpoint temperature $\left({ }^{\circ} \mathrm{C}\right)$

$F=$ Mean surface windspeed $\left(\mathrm{ms}^{-1}\right)$

$\mathrm{P}=\mathrm{M}$ ean Pasquill-Tumer stability index

$D=1$ if wind direction $\varepsilon(270,340)$ degrees

$=0$ otherwise

Table 4 Multiple regression analysis of daily mean smoke pollution data for Ballyfermot. 